\title{
SUBSTRATE CARRIERS FOR C-1(2)-DEHYDROGENATION OF 6-METHYLENE ANDROSTENEDIONE TO EXEMESTANE BY GROWING AND IMMOBILIZED ARTHROBACTER SIMPLEX NCIM 2449
}

\author{
PRACHI PATIL ${ }^{1 *}$, RAJESH SHARMA ${ }^{1}$, TUSHAR BANERJEE ${ }^{2}$, SHRIDHAR PATIL ${ }^{2}$ \\ ${ }^{1}$ School of Pharmacy, Devi Ahilya University, Indore - 452 001, Madhya Pradesh, India. ${ }^{2}$ School of Life Sciences, Devi Ahilya University, \\ Indore - 452001, Madhya Pradesh, India. Email: prachi2607@gmail.com
}

Received: 25 October 2016, Revised and Accepted: 14 November 2016

\section{ABSTRACT}

Objective: Permeability of hydrophobic steroid substrates across cell membrane is a critical factor during microbial bioconversion. To increase substrate intake, the feasibility of some organic solvents and emulsifiers as a substrate carrier on the bioconversion of 6-methylene androstenedione (6-MeAD) to exemestane was assessed.

Methods: AD, a commonly available steroid precursor, was chemically converted 6-MeAD. The time course of exemestane accumulation was estimated after addition of 6-MeAD dissolved in some organic solvents or dispersed with emulsifiers by growing and immobilized cells of Arthrobacter simplex NCIM 2449 in shake flask cultures.

Results: The use of substrate carriers for addition of 6-MeAD enhanced the bioconversion several folds. With growing bacterium in triplicate flasks, a peak mol \% bioconversion recorded was- ethanol (67.25, $72 \mathrm{hrs})$; soybean oil + tween 80 (50.37, $48 \mathrm{hrs);} \mathrm{acetone} \mathrm{(38.84,} 48 \mathrm{hrs)}$; soybean oil (38.36, $48 \mathrm{hrs})$; lecithin $(32.73,48 \mathrm{hrs})$, methanol $(32.71,48 \mathrm{hrs})$ and tween 80 (10.37, $48 \mathrm{hrs})$. As compared to the growing cells, the bioconversion with Ca-alginate immobilized cells was delayed, and peak mol \% bioconversion was recorded as ethanol (60.78, $120 \mathrm{hrs);} \mathrm{soybean}$ oil + tween 80 (42.98, $120 \mathrm{hrs);} \mathrm{methanol} \mathrm{(40.50,} 72 \mathrm{hrs);} \mathrm{soybean} \mathrm{oil} \mathrm{(38.36,} 48 \mathrm{hrs)}$; acetone (31.18, $72 \mathrm{hrs})$, and lecithin (33.67, $120 \mathrm{hrs);} \mathrm{tween}$ $80(13.87,120 \mathrm{hrs})$.

Conclusion: The use of substrate carriers for addition of 6-MeAD increased the permeability of substrate and may be used to increase the yield of exemestane and reduce incubation time.

Keywords: Steroid substrate carrier, Exemestane, Arthrobacter simplex NCIM 2449, Breast cancer, Steroid C-1(2)-dehydrogenation, 3-ketosteroiddelta-1-dehydrogenase.

(c) 2017 The Authors. Published by Innovare Academic Sciences Pvt Ltd. This is an open access article under the CC BY license (http://creativecommons. org/licenses/by/4. 0/) DOI: http://dx.doi.org/10.22159/ajpcr.2017.v10i2.15861

\section{INTRODUCTION}

Exemestane (6-methylene androstadienedione $[\mathrm{ADD}])$ is a suicidal aromatase inhibitor that lowers estrogen production in the body [1]. This drug is being used individually for the treatment of postmenopausal breast cancer patients [2] and under Phase III trial valuation in combination with bevacizumab [3]. Various schemes have been patented for chemical synthesis of exemestane depending on starting precursor such as androstenedione (AD) [4,5], boldenone [6], ADD [7], 6-methylene AD (6-MeAD) [8], and testosterone [9]. However, the involvement of multiple steps, use of hazardous chemicals like selenium oxide and 2,3-dichloro-5,6-dicyano-1,4-benzoquinone required for the final step of C-1(2)-dehydrogenation and formation of extremely toxic hydrocyanic acid gas make these methods undesirable for the synthesis of exemestane. The sequence of reactions involved in the synthesis of exemestane from $\mathrm{AD}$ is presented in Fig. 1.

Alternative to the hazardous chemical reaction, biochemical reactions catalyzed by enzymes are preferred. Several microbial genera are known to secrete an enzyme 3-ketosteroid- $\Delta^{1}$-dehydrogenase (ksdD, EC 1.3.99.4), which catalyzes C-1(2)-dehydrogenation of a variety of steroid substrates. Arthrobacter simplex has been frequently used for C-1(2)-dehydrogenation of steroids substrates such as hydrocortisone to prednisolone $[10,11]$ and 16-methyl Reichstein's compound S-21 acetate [12]. Resting cells of $A$. simplex have also been used for the bioconversion of 6-MeAD to exemestane in the presence of water immiscible organic solvent and an exogenous electron carrier [13].
Microbial C-1(2)-dehydrogenation of 6-MeAD to exemestane by Nocardioides simplex VKM Ac-2033D has also been reported,and the process is patented $[14,15]$.

Aggregation of steroidal substrate particles pose major mass transfer problem that decreases the bioavailability of substrate during the bioconversion, and a variety of methods have been adopted to obtain finely dispersed suspension of the substrate in the medium. Frequently, steroidal substrates have been added in the form of their solution in water miscible organic carrier solvents such as ethanol, dimethylformamide, acetone, dimethylsulphoxide, and methanol [16-19]. However, this method has limitations imposed by the toxic effect of the carrier solvents on the microorganisms at higher concentrations.

Water-immiscible organic solvents have also been used in biphasic systems and the toxicity exerted by various organic solvents and solvent mixtures on steroid-1(2)-dehydrogenase activity of $A$. simplex have been worked out [20]. The use of natural oils as carriers yielded higher conversion of soybean sterols to 17 -ketosteroids by mycobacteria [21,22]. Using lecithin and tween 80 as substrate dispersing agents, higher yields of ADD have been reported [23,24]. This work was carried out to assess the feasibility of some organic solvents and emulsifiers as dispersing agents to increase mass transfer of substrate so that an efficient and eco-friendly alternative for $\mathrm{C}-1(2)$-dehydrogenation of 6-MeAD to exemestane can be developed. 


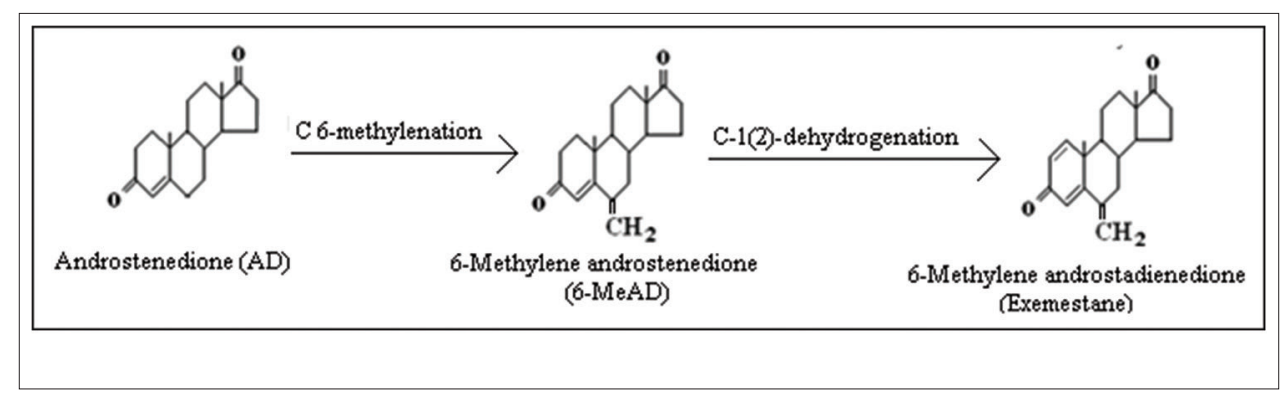

Fig. 1: Sequence of reactions involved in the synthesis of exemestane from androstenedione.

\section{METHODS}

\section{Synthesis of 6-MeAD}

$A D$ procured from Jagsonpal Pharmaceuticals, New Delhi was converted to 6-MeAD following the method disclosed earlier [25] with suggested modification [26] as follows: $10 \mathrm{~g}$ of $\mathrm{AD}$ was dissolved in solvent mixture of $50 \mathrm{ml}$ dioxane, $12 \mathrm{ml}$ trimethylorthoformate and $10 \mathrm{ml}$ absolute ethyl alcohol, heated to $45^{\circ} \mathrm{C}$ on a magnetic stirrer and $0.6 \mathrm{~g} p$-toluenesulfonic acid was added. After $1 \mathrm{hr}, 4 \mathrm{ml} \mathrm{N}$-methyl aniline and $4.5 \mathrm{ml}$ formaldehyde (37\%) were added, and the reaction was continued for $3 \mathrm{hrs}$ at $50^{\circ} \mathrm{C}$. The reaction solution was cooled to $0^{\circ} \mathrm{C}$, acidified by dropwise addition of $25 \mathrm{ml}$ concentrated $\mathrm{HCl}$ and the reaction was continued further for $1 \mathrm{hr}$ at $5^{\circ} \mathrm{C}$. The reaction solution was diluted with $500 \mathrm{ml}$ distilled water pre-cooled to $10^{\circ} \mathrm{C}$, stirred for $1 \mathrm{hr}$ and the precipitated solids were filtered, washed with pre-cooled $80 \mathrm{ml}$ distilled water and vacuum dried. The dried precipitate was dissolved in $40 \mathrm{ml}$ ethanol, decolorized with charcoal and crystallized from the filtrate. The crystalline product was dried under vacuum, weighed and subjected to thin layer chromatography (TLC), ultraviolet (UV), and infrared (IR) spectroscopic analyses.

\section{Organism}

Arthrobacter simplex NCIM 2449 was purchased from National Collection of Industrial Microorganisms, National Chemical Laboratory, Pune.

\section{Bioconversion of 6-MeAD by growing cells}

About $30 \mathrm{ml}$ nutrient broth ( $\mathrm{pH} \mathrm{7.2)} \mathrm{was} \mathrm{dispensed} \mathrm{in} 150 \mathrm{ml}$ capacity Erlenmeyer flask, and $30 \mathrm{mg}$ 6-MeAD was dispersed with glass beads on a gyratory shaker (control). Alternatively, the substrate was dissolved in $0.5 \mathrm{ml}$ water soluble carrier (methanol/ethanol/acetone) and added to the medium with continuous stirring. When soybean oil was used as a carrier, $30 \mathrm{mg}$ substrate was dissolved in $4.8 \mathrm{ml}$ soybean oil or soybean oil containing $5 \mathrm{mg}$ tween 80 and added to the medium. In case of lecithin ( $5 \mathrm{mg}$, hydrated with $1 \mathrm{ml}$ distilled water) and tween 80 (5 mg), each of these ingredients was macerated with the $30 \mathrm{mg}$ substrate in pestle and mortar and dispersed by addition of nutrient broth to make up the volume to $30 \mathrm{ml}$. After sterilization at $121^{\circ} \mathrm{C}$ for 15 minutes, the flasks were inoculated aseptically with $1 \mathrm{ml}$ actively growing culture of A. simplex NCIM 2449 and incubated at $32 \pm 1^{\circ} \mathrm{C}$ on a gyratory incubator shaker (180 rpm, $2.5 \mathrm{~mm}$ eccentric throw).

\section{Bioconversion of 6-MeAD by Ca-alginate immobilized cells}

The method described by Kierstan and Bucke was adopted for immobilization of microbial biomass [27]. A. simplex NCIM 2449 was grown in four $500 \mathrm{ml}$ capacity Erlenmeyer flasks, each containing $100 \mathrm{ml}$ nutrient broth adjusted to $\mathrm{pH}$ 7.3. After sterilization, the flasks were inoculated with actively growing culture of A. simplex NCIM 2449 and incubated at $32 \pm 1^{\circ} \mathrm{C}$ on gyratory incubator shaker. After $72 \mathrm{hrs}$ growth period, the biomass was aseptically harvested by centrifugation at $10,000 \mathrm{rpm}$ for 10 minutes, washed twice with $0.85 \%$ saline and suspended in $200 \mathrm{ml}$ sodium alginate solution. After thorough mixing on a cyclomixer, the alginate-biomass mixture was added dropwise through syringe into chilled $0.2 \mathrm{M}$ calcium chloride solution. The beads were hardened overnight in $0.2 \mathrm{M}$ calcium chloride solution at $4^{\circ} \mathrm{C}$, washed with phosphate buffer (pH 7.0, $0.07 \mathrm{M})$ and stored in $0.02 \mathrm{M}$ calcium chloride solution at $4^{\circ} \mathrm{C}$ in refrigerator. For bioconversion, $10 \mathrm{~g}$ beads were taken in $150 \mathrm{ml}$ flasks containing $30 \mathrm{ml}$ sterile phosphate buffer ( $\mathrm{pH} 7.0,0.07 \mathrm{M})$. The substrate 6-MeAD was added to the reaction buffer as described above replacing buffer in place of nutrient and incubated on a gyratory incubator shaker at $32 \pm 1^{\circ} \mathrm{C}$. Samples of reaction buffer were taken after regular intervals and processed for qualitative and quantitative analyses.

\section{TLC}

The samples of the incubation medium or reaction buffer were drawn periodically and subjected to qualitative and quantitative analysis of exemestane. To $1 \mathrm{ml}$ sample of medium in an eppendroff tube, $0.5 \mathrm{ml}$ chloroform was added and thoroughly mixed on a cyclomixer. After centrifugation at $5000 \mathrm{rpm}$ for 5 minutes, lower chloroform phase was transferred to another tube and dried over anhydrous sodium sulfate. $10 \mu \mathrm{l}$ extract was spotted on pre-coated TLC plates (silica gel 60 F254, Merck, Darmstadt) along with authentic sample of exemestane obtained from Cipla Ltd., Mumbai, India, and the plates were developed in benzene-ethyl acetate $5: 2)$. The spots were visualized by spraying the plate with $50 \%$ sulfuric acid followed by heating at $110^{\circ} \mathrm{C}$ for 5 minutes. In the case of oil as carrier solvent, sample of incubation medium was centrifuged at $10,000 \mathrm{rpm}$ for 10 minutes, $0.1 \mathrm{ml}$ oil phase was transferred to another eppendroff tube, mixed thoroughly with $0.5 \mathrm{ml}$ methanol on a cyclomixer, centrifuged at $10,000 \mathrm{rpm}$ for 10 minutes and upper methanolic phase was dried under vacuum. The residue was dissolved in $0.5 \mathrm{ml}$ chloroform and subjected to TLC analysis as described above. Identification of exemestane spot on TLC plate was done by comparison of $R_{f}$ value, color of the spot with authentic sample and spectroscopic methods.

\section{Quantification of exemestane}

Chloroform extract of the incubation medium $(0.25 \mathrm{ml})$ was dried under vacuum, the residue was dissolved in $0.5 \mathrm{ml}$ acetonitrile, filtered and $10 \mu \mathrm{l}$ was subjected to high-performance liquid chromatography (HPLC) analysis as described earlier [28]. The specifications and the parameters of HPLC analysis were: Equipment JASCO Make, Model 1580; column: ODS HYPERSIL C $18(250 \mathrm{~mm} \times 4.6 \mathrm{~mm})$; column temperature $45^{\circ} \mathrm{C}$; Detection wavelength $245 \mathrm{~nm}$; mobile phase acetonitrile: water (60:40); flow rate $0.45 \mathrm{ml} / \mathrm{min}$; total run time 20 minutes, injection volume $10 \mu \mathrm{l}$.

Bioconversion, isolation, and purification of exemestane Bioconversion of 6-MeAD was carried out in six $500 \mathrm{ml}$ capacity Erlenmeyer flasks, each containing $100 \mathrm{ml}$ nutrient broth. Substrate 100 $\mathrm{mg}$ dissolved in $2 \mathrm{ml}$ ethanol was added in each flask with continuous stirring, sterilized and inoculated with $5 \mathrm{ml}$ actively growing culture of A. simplex NCIM 2449. After 96 hrs incubation on gyratory shaker, the fermentation broth of all flasks was combined and extracted with $3 \mathrm{ml} \times 100 \mathrm{ml}$ chloroform. The chloroform extract was dried over anhydrous sodium sulfate and chloroform was recovered in rotary flash evaporator. The obtained residue was dissolved in ethyl acetate, decolorized with charcoal; the filtrate was concentrated to $30 \mathrm{ml}$ and cooled to $4^{\circ} \mathrm{C}$ in refrigerator for crystallization. Crystals separated after overnight cooling were collected by filtration, washed with chilled ethyl acetate and dried under vacuum. 


\section{RESULTS}

Identification of product of chemical synthesis

$10 \mathrm{~g}$ of $\mathrm{AD}$ taken for chemical synthesis yielded $7.136 \mathrm{~g}$ of crystalline product, which was identified as 6-MeAD on the basis of following characteristics:

- Color of spot on TLC plate: Bluish green; $\mathrm{R}_{\mathrm{f}}-0.46$ (Fig. 2a)

- UV absorption spectrum: $\lambda_{\max } 261.4 \mathrm{~nm}$ (Fig. $2 \mathrm{~b}$ )

- IR spectrum (KBr): Peaks, $\mathrm{cm}^{-1}$ at 3832.3, $3793.7\left(6-\mathrm{CH}_{2}\right),(17-\mathrm{C}=0)$; 1454.2 and $1334.6\left(\Delta^{4}-3-C=0\right)$.

- The molar yield of 6-MeAD was $68.48 \mathrm{~mol} \%$.

Identification of bioconversion product

A total of $500 \mathrm{mg}$ 6-MeAD was added in five bioconversion flasks and yielded $245 \mathrm{mg}$ crystalline product. The product was identified as exemestane on the basis of following characteristics:

- Color of spot on co-TLC plate: Reddish pink; $\mathrm{R}_{\mathrm{f}}-0.40$ (Fig. 2a)
- UV absorption spectrum: $\lambda 245.5$ nm (Fig. 2c)

- The molar yield of exemestane was $49.33 \mathrm{~mol} \%$.

HPLC analysis of crystalline bioconversion product indicated a single peak (Fig. 3) at average retention time ( 6 runs) at $11.67 \pm 0.28$ minutes (mean \pm standard deviation). A fairly proportional relationship was observed between exemestane concentration $(2.5,5.0,7.5$ and 10.0 $\mu \mathrm{g} / \mathrm{ml})$ and peak area $\left(\mathrm{r}^{2}=0.9855\right)$ and was used for quantification of exemestane formed during the bioconversion.

Mole \% bioconversion of 6-MeAD to exemestane by growing cells of A. simplex NCIM 2449 with different carriers is presented in Table 1. In the case of control and tween 80 , no exemestane was detected in the medium at $24 \mathrm{~h}$ incubation period, whereas a rapid accumulation of exemestane was recorded with other carriers. As compared to control, the use of all other substrate carriers increased C-1(2)-dehydrogenation activity of A. simplex NCIM 2449. Peak bioconversion was recorded

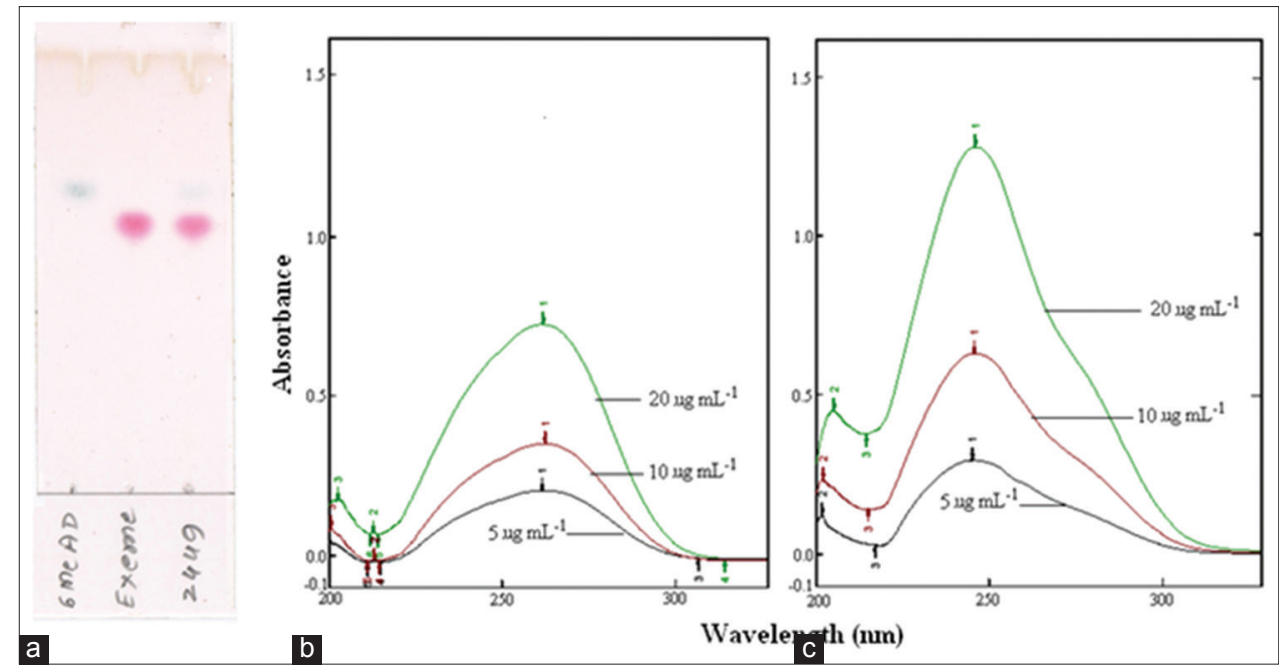

Fig. 2: Thin layer chromatography scan (a) and ultraviolet absorption spectra of 6-methylene androstenedione (b) and exemestane (c)

Table 1: Mol \% bioconversion of 6-MeAD to exemestane by growing cells of A. simplex NCIM 2449

\begin{tabular}{|c|c|c|c|c|c|}
\hline \multirow[t]{2}{*}{ Substrate carrier } & \multicolumn{5}{|c|}{ Mol \% bioconversion \pm SD after incubation period (hrs) } \\
\hline & 24 & 48 & 72 & 96 & 120 \\
\hline Control & nd & nd & $3.45 \pm 0.30$ & $7.45 \pm 0.32$ & $15.07 \pm 0.45$ \\
\hline Methanol & $31.53 \pm 1.81$ & $32.71 \pm 2.05$ & $20.53 \pm 0.93$ & $18.31 \pm 1.13$ & $16.10 \pm 0.09$ \\
\hline Ethanol & $29.45 \pm 2.30$ & $55.6 \pm 2.05$ & $67.25 \pm 3.04$ & $63.19 \pm 2.96$ & $60.68 \pm 0.36$ \\
\hline Acetone & $25.88 \pm 1.90$ & $38.84 \pm 1.62$ & $25.31 \pm 1.87$ & $23.67 \pm 1.33$ & $23.32 \pm 1.26$ \\
\hline Soybean oil & $34.52 \pm 1.63$ & $38.36 \pm 1.92$ & $24.22 \pm 1.75$ & $20.14 \pm 1.52$ & $18.73 \pm 0.98$ \\
\hline Soybean oil+tween 80 & $38.97 \pm 2.02$ & $50.37 \pm 2.21$ & $32.62 \pm 2.30$ & $28.44 \pm 1.56$ & $28.02 \pm 1.44$ \\
\hline Tween 80 & nd & $10.37 \pm 1.69$ & $6.90 \pm 0.64$ & $3.42 \pm 0.44$ & $4.09 \pm 0.56$ \\
\hline Lecithin & $30.11 \pm 2.14$ & $32.73 \pm 1.70$ & $21.84 \pm 1.91$ & $21.27 \pm 1.49$ & $18.55 \pm 1.52$ \\
\hline
\end{tabular}

SD: Standard deviation ( $\mathrm{N}=3$ ), nd: Not detected, A. simplex: Arthrobacter simplex, 6-MeAD: 6-methylene androstenedione, NCIM: National Collection of Industrial

Microorganisms

Table 2: Mol \% conversion of 6-MeAD to exemestane by Ca-alginate immobilized cells of $A$. simplex NCIM 2449

\begin{tabular}{llllll}
\hline Substrate carrier & \multicolumn{4}{l}{ Mol \% bioconversion \pm SD after incubation period (hrs) } & \\
\cline { 2 - 6 } & $\mathbf{2 4}$ & $\mathbf{4 8}$ & $\mathbf{7 2}$ & $\mathbf{9 6}$ & $\mathbf{1 2 0}$ \\
\hline Control & nd & nd & nd & $2.65 \pm 0.34$ & $8.60 \pm 0.50$ \\
Methanol & $18.46 \pm 0.91$ & $38.78 \pm 1.84$ & $40.50 \pm 1.79$ & $36.85 \pm 1.97$ & $35.88 \pm 1.50$ \\
Ethanol & $19.53 \pm 1.34$ & $36.55 \pm 3.06$ & $56.39 \pm 3.14$ & $57.29 \pm 3.40$ & $60.78 \pm 2.97$ \\
Acetone & $14.18 \pm 1.12$ & $17.27 \pm 1.42$ & $31.18 \pm 1.76$ & $29.54 \pm 1.43$ & $30.13 \pm 1.33$ \\
Soybean oil & $34.52 \pm 1.63$ & $38.36 \pm 1.92$ & $24.22 \pm 1.75$ & $20.14 \pm 1.52$ & $18.74 \pm 0.97$ \\
Soybean oil+tween 80 & $12.05 \pm 1.04$ & $25.40 \pm 1.97$ & $40.11 \pm 3.78$ & $40.32 \pm 3.17$ & $42.98 \pm 2.02$ \\
Tween 80 & nd & nd & $8.36 \pm 0.96$ & $12.54 \pm 0.87$ & $13.87 \pm 1.05$ \\
Lecithin & $15.32 \pm 0.73$ & $21.61 \pm 1.13$ & $25.89 \pm 1.83$ & $28.12 \pm 2.11$ & $33.67 \pm 2.88$ \\
\hline
\end{tabular}

SD: Standard deviation ( $\mathrm{N}=3$ ), nd: Not detected, A. simplex: Arthrobacter simplex, NCIM: National Collection of Industrial Microorganisms 


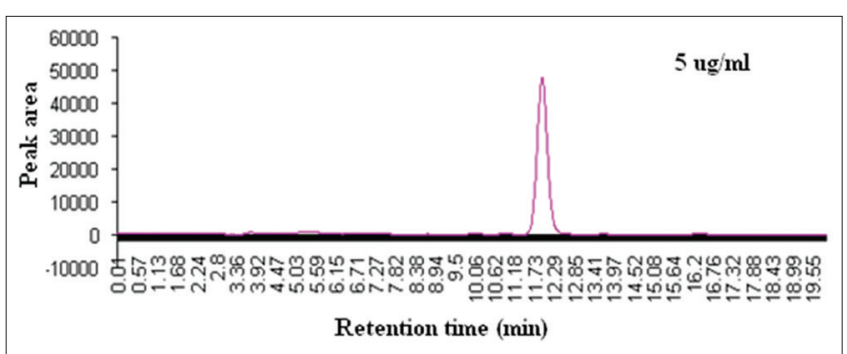

Fig. 3: High-performance liquid chromatography chromatogram of exemestane

at $48 \mathrm{hrs}$ incubation period with exception of ethanol as a substrate carrier, which was observed at 72 hrs. A decline in the exemestane content of the medium was observed after reaching a peak, indicating the degradation of this compound by A. simplex NCIM 2449.

Table 2 shows the mol \% conversion of 6-MeAD to exemestane by Ca-alginate immobilized cells of $A$. simplex NCIM 2449. Although the overall bioconversion indicated similar pattern as observed with growing cells, a delay in peak bioconversion was noted. Among various carriers used, the highest bioconversion was recorded again with ethanol as a substrate carrier till the end of incubation period at 120 hrs, indicating the suitability of ethanol for 1(2)- dehydrogenation activity of Ca- alginate immobilized cells of A. simplex NCIM 2449.

\section{DISCUSSION}

Permeability of hydrophobic steroid substrate across bacterial cell membrane plays a key role in bioconversion catalyzed by enzymes present inside the bacterial cell. The data obtained during this work clearly indicated an enhanced bioconversion when 6-MeAD was added in dissolved form in organic solvents or dispersed with emulsifiers. The enhancement in the bioconversion activity of A. simplex in the presence of organic solvents has been attributed to increased permeability of cell membrane to steroidal substrates [29]. The analysis of cell membrane of A. simplex grown in the presence of ethanol revealed an increment in cis-isomers of unsaturated fatty acids, thereby disorganization of native arrangement, resulting in increased permeability to steroid substrates [16]. In another study, reduction in the unsaturated and long chain fatty acids of A. simplex membrane in the presence of hydroxypropyl- $\beta$-cyclodextrin has been reported [30]. This study indicated that the organic solvents, soybean oil and lecithin increased the permeability of 6-MeAD, and resulted in early and higher bioconversion. Tween 80 alone proved deleterious to the bioconversion but favored the process when added along with soybean oil. It can be concluded that this anionic detergent lysed A. simplex cells at $5 \mathrm{mg} / 30 \mathrm{ml}$ concentration when used alone. Similar observation was recorded during $9 \alpha$-steroid hydroxylation by Rhodococcus sp. [31]. In comparison with the earlier reports of bioconversion of 6-MeAD to exemestane by A. simplex in xylene-water two-phase system [32] and $\beta$-cyclodextrin complexation technique [33], higher bioconversion was achieved in the present work.

The stability of C-1(2)-dehydrogenase activity of A. simplex cells immobilized in Ca-polygalacturonate [34], Ca- alginate [35], $k$-carrageenan beads, and polyurethane foam [36] has been shown against a variety of steroid substrates. The present work indicated the use of growing and Ca-alginate immobilized A. simplex cells as an environment-friendly alternative for 1(2)-dehydrogenation of 6-MeAD to exemestane.

Since exemestane is degraded simultaneously along with its formation both by growing as well as Ca-alginate immobilized cells of $A$. simplex NCIM 2449, the amount of exemestane accumulated in the fermentation broth is a result of rate of its formation and degradation. Therefore, precise termination of bioconversion reaction is suggested to harvest maximum product.

\section{CONCLUSION}

C-1(2)-dehydrogenase activity of growing and Ca-alginate immobilized A. simplex NCIM 2449 cells can be exploited for the bioconversion of 6-MeAD to exemestane. To overcome the steroid permeability barrier, 6-MeAD may be dispersed in the incubation medium using ethanol as substrate carrier. This organism and the described process may be scaled up to replace the hazardous chemical reaction by eco-friendly microbial bioconversion.

\section{ACKNOWLEDGMENT}

We thank Jagsonpal Pharmaceuticals, New Delhi for providing AD required for the present study.

\section{REFERENCES}

1. Brueggemeier RW, Hackett JC, Diaz-Cruz ES. Aromatase inhibitors in the treatment of breast cancer. Endocr Rev 2005;26(3):331-45.

2. Goss PE, Ingle JN, Alés-Martínez JE, Cheung AM, Chlebowski RT, Wactawski-Wende J, et al. Exemestane for breast-cancer prevention in postmenopausal women. N Engl J Med 2011;364(25):2381-91.

3. Trédan O, Follana P, Moullet I, Cropet C, Trager-Maury S, Dauba J, et al. A phase III trial of exemestane plus bevacizumab maintenance therapy in patients with metastatic breast cancer after first-line taxane and bevacizumab: A GINECO group study. Ann Oncol 2016;27(6):1020-9.

4. Agarwal VK, Singh MK, Patel AM, Solanki K. Process for preparing aromatase inhibitor exemestane. US Patent, 8288571 B2; 2012.

5. Buzzetti F, Barbugian N, Lombardi P, di Salle E. 6-substituted androsta1,4-diene-3,17-diones. US Patent 4808616; 1989.

6. Longo A, Lombardi P. Process for the preparation of methylene derivatives of androsta-1,4-diene-3,17-dione. US Patent 4876045; 1989.

7. Kunnen K, Stehle NW, Weis SW, Pascone JM, Pariza RJ, Van Ornum SG, et al. Exemestane and its intermediates and methods of making the same. WO Patent 2005070951; 2005.

8. Agarwal VK, Singh MK, Patel AM, Solanki K. Process for preparing aromatase inhibitor exemestane. PCT Patent WO 2009/093262 A2; 2009.

9. Marcos-Escribano A, Bermejo A, Bonde-Larsen FA, Retuerto AL, Sierra IH. 1,2-dehydrogenation of steroidal 6-methylen derivatives. Synthesis of exemestane. Tetrahedron 2009;65(36):7587-90.

10. Hocknull MD, Lilly MD. Stability of the steroid $\Delta 1$-dehydrogenation system of Arthrobacter simplex in organic solvent-water two liquid phase environments. Enzyme Microb Technol 1988;10(11):669-74.

11. Vlahov R, Pramatarova V, Spassov G, Suchodolskaya GV, Koshcheenko KA. Transformation of microcrystalline hydrocortisone by free and immobilized cells of Arthrobacter simplex. Appl Microbiol Biotechnol 1990;33(2):172-5.

12. Smolders AJ, Pinheiro HM, Noronha P, Cabral JM. Steroid bioconversion in a microemulsion system. Biotechnol Bioeng 1991;38(10):1210-7.

13. Krook MA, Hewitt BD. Process to prepare exemestane. PCT Patent WO 01/04342; 2001

14. Sukhodolskaya GV, Fokina VV, Savinova TS, Shutov AA, Lukashev NV, Donova MV. Combined chemical and microbiological synthesis of exemestane from sitosterol. J Biotechnol 2010;150 Suppl 1:189.

15. Savinova TS, Lukashev NV, Sukhodolskaya GV, Donova MV, Fokina VV, Shutov AA, et al. Method for obtaining 6- methyleneandrost4-ene-3,17-dione and obtaining of 6-methylene androsta-1,4diene-3,17-dione (exemestane) from 6- methyleneandrost-4-ene-3,17dione thereof. Russian Patent 2425052; 2011.

16. Luo J, Ning J, Wang Y, Cheng Y, Zheng Y, Shen Y, et al. The effect of ethanol on cell properties and steroid 1-en-dehydrogenation biotransformation of Arthrobacter simplex. Biotechnol Appl Biochem 2014;61(5):555-64.

17. Pendharkar GB, Anjum, SD, Patil S. Enhanced biotransformation of phytosterols, a byproduct of soybean refineries, to a key intermediate used for synthesis of steroidal drugs. Asian J Pharm Clin Res 2014;7(4):178-80

18. Vadalkar K, Gupta FC, Bhat HK, Chopra CL. Bioconversion of pregnenolone to ADD by Arthrobacter simplex. Indian J Exp Biol $1980 ; 18: 245-8$.

19. Somal P, Chopra CL. Microbial conversion of steroids II: 11 $\alpha$-hydroxylation by fungal spores. Res Ind 1982;27:170-3 .

20. Pinheiro HM, Cabral JM. Effects of solvent molecular toxicity and 
microenvironment composition on the $\Delta^{1}$-dehydrogenataon activity of Arthrobacter simplex cells. Biotechnol Bioeng 1991;37(2):97-102.

21. Phase N, Patil S. Natural oils are better than organic solvents for the conversion of soybean sterols to 17-ketosteroids by Mycobacterium fortuitum. World J Microbiol Biotechnol 1994;10(2):228-9.

22. Xu YG, Guan YX, Wang HQ, Yao SJ. Microbial side-chain cleavage of phytosterols by mycobacteria in vegetable oil/aqueous two-phase system. Appl Biochem Biotechnol 2014;174(2):522-33.

23. Wang ZF, Huang YL, Rathman JF, Yang ST. Lecithin-enhanced biotransformation of cholesterol to androsta-1,4-diene-3,17dione and androsta-4-ene-3,17-dione. J Chem Technol Biotechnol 2002;77(12):1349-57.

24. Luthra U, Khadpekar S, TrivediA, ShettyA, Kumar H. Biotransformation of 4-androstene-3,17-dione by Nocardioides simplex. World J Pharm Pharm Sci 2015;4(11):935-43.

25. Longo A, Lombardi P. Synthesis of 6-methylene derivatives of androsta-1,4-diene-3,17-dione. U S Patent 4990635; 1991.

26. Aggarwal AK, Jain AK, Chidambaram VS, Wadhawa L. Process for the preparation of exemestane. PCT Patent WO 078811 A2; 2010

27. Kierstan M, Bucke C. The immobilization of microbial cells, subcellular organelles, and enzymes in calcium alginate gels. Biotechnol Bioeng 1977;19(3):387-97.

28. Yuvuz B, Bilensoy E, Sumnu M. Analytical method validation for HPLC assay of oral anticancer drug exemestane. FABAD J Pharm Sci 2007;32:15-22.

29. Luo JM, Song Y, Wang JF, Ning J, Cheng YX, Cheng, et al. Study on the effects of different kinds of organic solvents on C 1,2 dehydrogenation reaction by the analysis of Arthrobacter simplex cell characters. Chem Bioeng 2012;29:49-53

30. Shen Y, Liang J, Li H, Wang M. Hydroxypropyl-ß-cyclodextrinmediated alterations in cell permeability, lipid and protein profiles of steroid-transforming Arthrobacter simplex. Appl Microbiol Biotechnol 2015;99(1):387-97.

31. Avramova T, Spassova D, Mutafov S, Momchilova S, Boyadjieva L, Damyanova B, et al. Effect of tween 80 on $9 \alpha$-steroid hydroxylating activity and ultrastructural characteristics of Rhodococcus sp. Cells. World J Microbiol Biotechnol 2010;26:1009-14.

32. Chen R, Li G, Zhang J, Liu F, Peng ZH, Deng L. Study on microbial transformation of exemestane in two-phase system. J Nat Sci Hunan Norm Univ 2010;2:24

33. Li G, Li F, Deng L, Fang X, Zou H, Xu K, et al. Increased yield of biotransformation of exemestane with $\beta$-cyclodextrin complexation technique. Steroids 2013;78(11):1148-51.

34. Montes MC, Magaña I. Delta'-dehydrogenation of steroids by Arthrobacter simplex immobilized in calcium polygalacturonate beads. J Ind Microbiol 1991;8(4):259-64.

35. Hocknull MD, Lilly MD. The use of free and immobilised Arthrobacter simplex in organic solvent/aqueous two-liquid-phase reactors. Appl Microbiol Biotechnol 1990;33(2):148-53.

36. Pinheiro HM, Cabral JM. Activity and stability of an entrapped-cell system for the $\Delta^{1}$-dehydrogenation of steroids in organic media. Biotechnol Bioeng 1992;40(9):1123-7. 